\title{
Corneal toxicity secondary to inadvertent use of benzalkonium chloride preserved viscoelastic material in cataract surgery
}

\author{
H Eleftheriadis, M Cheong, S Sandeman, P P Syam, P Brittain, G K Klintworth, A Lloyd, \\ C Liu
} See end of article for
authors' affiliations

Correspondence to: Mr Christopher Liu, Sussex Eye Hospital, Brighton BN2 5BF, UK; cscliu@aol.com

Accepted for publication 10 October 2001

\begin{abstract}
Aims: To study the long term toxic effects of intraocular benzalkonium chloride (BAC).
Methods: 19 patients exposed to intraocular BAC preserved viscoelastic during cataract surgery in February 1999 developed severe striate keratopathy immediately postoperatively. 16 patients, including two who underwent penetrating keratoplasty, were studied in the period April to June 2000. Ocular symptoms, visual acuity, biomicroscopy, intraocular pressure, dilated funduscopy, specular endothelial microscopy, and corneal pachymetry findings were recorded. The corneal and iris specimens of the two patients who underwent keratoplasty were studied by light, transmission, and scanning electron microscopy.

Results: Six males and 10 females, aged 64-98 years, were studied 14-16 months postoperatively. All patients were symptomatic. 12 patients had best corrected visual acuity of $6 / 12$ or better and four patients of between $6 / 18$ and $6 / 60$. Five patients had corneal epithelial oedema and 11 had Descemet's membrane folds. The central corneal thickness, 620 (SD 71) $\mu \mathrm{m}$, in affected eyes was significantly higher ( $p<0.005$, two tailed paired t test) than that of the contralateral eyes, 563 (SD 48) $\mu \mathrm{m}$. The endothelial cell density was significantly lower $(p<0.0001$, two tailed paired $t$ test) in affected eyes: 830 (SD 280) cells $/ \mathrm{mm}^{2}$ v 2017 (SD 446) cells $/ \mathrm{mm}^{2}$. The mean average cell area was significantly higher in the BAC treated eyes: 1317 (SD 385) $\mathrm{mm}^{2} v 521$ (SD 132) $\mathrm{mm}^{2}$. There was no significant difference in the coefficient of variation of cell size between the two eyes $(p=0.3$, two tailed paired $t$ test). Two corneal specimens displayed morphological features of bullous keratopathy and other nonspecific abnormalities. Extracellular melanosomes were present in a portion of the iris of one case. Conclusion: BAC is toxic to the corneal endothelium when used intraocularly, leading to severe striate keratopathy. This cleared in most cases but left varying degrees of residual stromal thickening in all eyes. If penetrating keratoplasty is required the results are excellent.
\end{abstract}

cessation of normal cytokinesis and mitotic activity, and degeneration of human corneal epithelial cells within 2 hours. ${ }^{17}{ }^{18} \mathrm{BAC}$ is toxic to all ocular tissues, ${ }^{16}{ }^{19-22}$ including the corneal endothelium. ${ }^{342324}$

We studied the corneal appearance and function of a cohort of patients who inadvertently received intraocularly BAC preserved viscoelastic material during cataract extraction.

\section{MATERIALS AND METHODS}

Clinical examination

Nineteen patients inadvertently received hydroxypropyl methylcellulose (HPMC) 2\% preserved with BAC $0.01 \%$ during phacoemulsification performed at another institution in February 1999, which resulted in severe postoperative corneal oedema. The BAC preserved HPMC was manufactured by the pharmacy department of Torbay Hospital, and was meant for external use only. The patients were reviewed regularly postoperatively, but they were formally studied during the period from April to June 2000. One patient died 1 month after the operation from an unrelated cause. One patient was unable to attend owing to poor health and one refused participation in the study. Therefore, 16 out of the original cohort of 19 patients were formally studied. Two patients (cases 14 and 15) underwent penetrating keratoplasty 4 months following their cataract surgery because of severe ocular pain secondary to bullous keratopathy. tration of $0.01 \%$ (the concentration used in most topical ophthalmic preparations) BAC causes immediate cell retraction, 


\begin{tabular}{|c|c|c|c|c|c|c|c|c|}
\hline Case No & Sex & Age & Eye & $\begin{array}{l}\text { Follow up } \\
\text { (months) }\end{array}$ & Notes & Preop VA & Postop VA & VA at study \\
\hline 1 & $M$ & 64 & $R$ & 14 & & CF & HM & $6 / 12$ \\
\hline 2 & $\mathrm{~F}$ & 74 & $R$ & 14 & & $3 / 60$ & $\mathrm{CF}$ & $6 / 18$ \\
\hline 3 & M & 78 & L & 14 & & $6 / 12-1$ & $H M$ & $6 / 9-1$ \\
\hline 4 & $M$ & 82 & $\mathrm{R}$ & 14 & & $6 / 18+1$ & $H M$ & $6 / 18$ \\
\hline 5 & $\mathrm{~F}$ & 88 & L & 15 & & $6 / 9$ & $\mathrm{CF}$ & $6 / 6$ \\
\hline 6 & $M$ & 78 & $R$ & 15 & & $6 / 9-3$ & $H M$ & $6 / 9$ \\
\hline 7 & $\mathrm{~F}$ & 67 & L & 15 & & $6 / 6-3$ & CF & $6 / 6$ \\
\hline 8 & $\mathrm{~F}$ & 80 & $R$ & 15 & & $6 / 60$ & $H M$ & $6 / 9$ \\
\hline 9 & $\mathrm{~F}$ & 79 & L & 15 & & $6 / 9$ & $\mathrm{CF}$ & $6 / 9+1$ \\
\hline 10 & $\mathrm{~F}$ & 90 & L & 15 & Not available for morphometric studies & $\mathrm{CF}$ & $\mathrm{CF}$ & $6 / 18$ \\
\hline 11 & M & 82 & $\mathrm{R}$ & 15 & & $6 / 9+3$ & $\mathrm{CF}$ & $6 / 6+2$ \\
\hline 12 & $\mathrm{~F}$ & 98 & L & 15 & & $6 / 18-1$ & $6 / 36$ & $6 / 12$ \\
\hline 13 & $\mathrm{~F}$ & 79 & L & 16 & & $6 / 24$ & HM & $6 / 12$ \\
\hline 14 & $F$ & 85 & $R$ & 16 & PK & $6 / 18$ & $\mathrm{CF}$ & $\begin{array}{l}\text { CF Pre-PK } \\
6 / 12 \text { Post-PK }\end{array}$ \\
\hline 15 & M & 74 & $\mathrm{R}$ & 16 & PK & $6 / 12-1$ & $H M$ & $\begin{array}{l}3 / 60 \text { Pre-PK } \\
6 / 9+1 \text { Post-PK }\end{array}$ \\
\hline 16 & $\mathrm{~F}$ & 81 & $\mathrm{R}$ & 16 & Specular microscopy not possible & $6 / 9$ & $\mathrm{CF}$ & $6 / 60+1$ \\
\hline
\end{tabular}

Preop VA, = preoperative BCVA; Postop VA = first visit BCVA; VA at study = BCVA at the time of study; PK = penetrating keratoplasty; HM = hand movements; $C F=$ counting fingers.

Ocular symptoms were sought with special attention paid to reduction and diurnal fluctuation of vision, pain, photophobia, and glare. Best corrected visual acuity (BCVA) was tested with a Snellen chart. Slit lamp biomicroscopy was performed with special consideration to corneal and iris changes. Intraocular pressure measurement and dilated funduscopy, after instillation of unpreserved eye drops of tropicamide $1 \%$ and phenylephrine $2.5 \%$, were performed in all cases.

\section{Morphometric analysis}

Specular endothelial microscopy of the central cornea was performed with a non-contact specular microscope (Topcon, model SP-2000P) and quantitative corneal endothelial cell analysis was done with a variable frame analysis method. ${ }^{25}$ Several microphotographs of the corneal endothelium were taken from the central area of each cornea and the one with best clarity was used for analysis. The maximum possible number of well defined endothelial cells (range 10-26 cells) was analysed. The number of the endothelial cells studied on each cornea varied owing to variations in cell size and the presence of Descemet's membrane folds obscuring clarity of the cell borders. The endothelial cell density (number of cells/ $\left.\mathrm{mm}^{2}\right)$, the average cell area $\left(\mu \mathrm{m}^{2}\right)$, and the coefficient of variation in cell size, an index of polymegathism, were obtained from both eyes and compared using the two tailed paired Student's $t$ test. A p value of less than 0.05 was considered statistically significant. One patient (case 10) was unavailable for specular microscopy and pachymetry. In one eye (case 16) specular microscopy was impossible in the study eye owing to severe corneal oedema. Although specular microscopy and pachymetry studies of the corneal grafts were performed on the two grafted patients their results have not been included in the statistical analysis.

\section{Pachymetry}

Central corneal thickness was measured (in $\mu \mathrm{m}$ ) in both eyes with an ultrasonic pachymeter (Quantel Medical Biovision International, France, Model Pocket) after instillation of Minims Benoxinate 0.4\% (oxybuprocaine, Chauvin). Five measurements from the central cornea were obtained and the average value was calculated. The corneal pachymetry measurements of the two eyes were compared using the two tailed paired Student's $t$ test.

\section{Tissue studies}

Corneal tissue obtained at penetrating keratoplasty and a portion of iris obtained at an iridectomy were processed for light and electron microscopy from cases 14 and 15. In both instances half of the corneal button was fixed in formalin and then processed for light microscopy. The remaining corneal tissue was fixed in glutaraldehyde and prepared for both scanning and transmission electron microscopy. The iris tissue was processed for transmission electron microscopy after thin sections were examined by light microscopy.

\section{RESULTS}

Demographic characteristics (Table 1)

The 16 studied patients (six male and 10 female) underwent phacoemulsification with polymethylmethacrylate intraocular lens (Storz, P359UV) implantation in February 1999. The operation was uneventful in all cases apart from two. One operation (case 6) was complicated by posterior capsular rupture with no vitreous loss and an intraocular lens was inserted in the ciliary sulcus. Another patient (case 11) developed peroperative miosis before capsulorhexis was attempted and the operation was abandoned and completed the following day. Seven patients had surgery in their left eye and nine patients in their right eye. All the patients except two (cases 8 and 10) had previously undergone uneventful phacoemulsification and intraocular lens implantation in the fellow eye. The mean age of the patients at the time of surgery was 79.9 (SD 8.3) years. The mean follow up period for the non-grafted patients was 14.9 (SD 0.7) months, whereas the two grafted patients (cases 14 and 15) were followed up at 12 months following corneal transplantation.

\section{Symptoms}

All 16 patients were still experiencing symptoms of variable severity in the BAC exposed eyes. The symptoms included blurring $(n=8)$, pain $(n=5)$, photophobia $(n=9)$, glare $(n=6)$, and diurnal fluctuation of vision $(\mathrm{n}=1)$. The two corneal grafted patients were also symptomatic, with case 14 complaining of photophobia and case 15 of pain, although their symptoms had improved considerably following penetrating keratoplasty. Seven patients had various symptoms in contralateral eyes including blurring $(n=3)$, photophobia $(n=7)$, and glare $(n=4)$. Four patients were asymptomatic in the fellow eyes and five patients were not asked.

\section{Visual results (Table 1)}

The preoperative BCVA ranged from 6/9 to counting fingers (CF). At the first postoperative visit (range 1-14 days after the operation) all patients were recorded as having significant 
Table 2 Clinical findings of patients in this study

\begin{tabular}{|c|c|c|c|c|c|c|c|}
\hline Case No & ECO & SCO & DMF & ECEC & Optic disc & Macula & Retina \\
\hline 1 & - & - & + & + & $\mathrm{N}$ & $\mathrm{N}$ & $\mathrm{N}$ \\
\hline 2 & + & + & + & + & $\mathrm{N}$ & $\mathrm{N}$ & $\mathrm{N}$ \\
\hline 3 & + & + & + & + & $\mathrm{N}$ & $\mathrm{N}$ & $\mathrm{N}$ \\
\hline 4 & - & - & + & + & $N$ & One MA & Choroidal naevus \\
\hline 5 & - & - & - & - & $\mathrm{N}$ & $\mathrm{N}$ & $\mathrm{N}$ \\
\hline 6 & - & - & + & + & $\mathrm{N}$ & $\mathrm{N}$ & Retinal scars \\
\hline 7 & - & - & + & + & $\mathrm{N}$ & $\mathrm{N}$ & $\mathrm{N}$ \\
\hline 8 & - & - & - & - & Cupped c/d 0.8 & $\mathrm{~N}$ & $\mathrm{~N}$ \\
\hline 9 & - & + & + & + & N & Drusen & $\mathrm{N}$ \\
\hline 10 & - & - & + & + & $\mathrm{N}$ & ARMD & $\mathrm{N}$ \\
\hline 11 & + & + & + & + & $\mathrm{N}$ & Drusen & Drusen \\
\hline 12 & - & - & - & - & $\mathrm{N}$ & $\mathrm{N}$ & $\mathrm{N}$ \\
\hline 13 & + & - & + & + & $\mathrm{N}$ & Drusen & $\mathrm{N}$ \\
\hline 14 & - & - & - & - & $\mathrm{N}$ & $\mathrm{N}$ & Drusen \\
\hline 15 & - & - & - & - & $\mathrm{N}$ & ARMD & $\mathrm{N}$ \\
\hline 16 & + & - & + & + & $N$ & Drusen & $\mathrm{N}$ \\
\hline
\end{tabular}

striate keratopathy and their BCVA was recorded as hand movement (HM) in seven patients, CF in eight patients, and $6 / 36$ in one patient. At the time of the study visit, 12 patients had BCVA $6 / 12$ or better and four patients between $6 / 18$ and 6/60 (Table 1).

The two patients who had undergone penetrating keratoplasty achieved BCVA of 6/9 and 6/12.

\section{Clinical results (Table 2)}

Corneal epithelial oedema, mainly localised around the corneal section, was seen in five patients, stromal oedema in four patients, Descemet's membrane folds in 11 patients (ranging from one to several folds) and biomicroscopically, using specular reflection, enlarged endothelial cells in 11 patients. The two corneal grafts remained clear (12 months post-keratoplasty), apart from a small Salzmann's nodule on the graft of one patient close to the graft-host junction (case 14).

Two patients (cases 1 and 15) had fluffy iris tags near the pupillary margin (bilaterally in case 15) and three patients had small, localised iris transillumination defects (cases 2, 11 , and 16). The posterior capsule was opacified in 14 eyes. Five eyes had had neodymium:YAG laser posterior capsulotomy and in the remaining nine eyes the opacification was not sufficiently significant to necessitate capsulotomy. The intraocular pressure was within normal limits in all patients and not different from the contralateral eyes. The pupil dilated well in 13 eyes while in three eyes mydriasis was poor. There was no clinical difference in the pharmacological mydriasis in the two eyes of any patient. Dilated funduscopic appearances are summarised in Table 2.

\section{Pachymetry (Table 3)}

The mean central corneal thickness of the study eyes, 620 (SD 71) $\mu \mathrm{m}$ was significantly higher $(\mathrm{p}<0.005)$ than the mean of the contralateral eyes, 563 (SD 48) $\mu \mathrm{m}$.

The central corneal thickness of the two corneal grafts was 503 and $536 \mu \mathrm{m}$ for cases 14 and 15 respectively.

\section{Specular endothelial microscopy (Table 3)}

The mean endothelial cell density was significantly lower $(\mathrm{p}<0.0001)$ in the BAC affected eyes: 830 (SD 280) cells $/ \mathrm{mm}^{2}$ compared with that of the fellow eyes: 2017 (SD 446) cells $/ \mathrm{mm}^{2}$. The mean average cell area of the study eyes was 1317 (SD 385) $\mathrm{mm}^{2}$, and it was significantly higher than that of the fellow eyes, 521 (SD 132) $\mathrm{\mu m}^{2}$. There was no significant

\begin{tabular}{|c|c|c|c|c|c|c|}
\hline Number & POE & PFE & ECDOE & ECDFE & ACAOE & ACAFE \\
\hline 1 & 724 & 670 & 958 & 1950 & 1043 & 512 \\
\hline 2 & 691 & 607 & 611 & 1896 & 1636 & 527 \\
\hline 3 & 565 & 471 & 857 & 2080 & 1166 & 480 \\
\hline 4 & 610 & 584 & 760 & 1684 & 1315 & 593 \\
\hline 5 & 537 & 552 & 626 & 2324 & 1597 & 430 \\
\hline 6 & 618 & 564 & 965 & 2199 & 1036 & 454 \\
\hline 7 & 589 & 568 & 713 & 2348 & 1402 & 425 \\
\hline 8 & 611 & 599 & 681 & 2820 & 1468 & 354 \\
\hline 9 & 564 & 517 & 503 & 1244 & 1988 & 803 \\
\hline 10 & \multicolumn{6}{|c|}{ Not available for pachymetry and specular microscopy } \\
\hline 11 & 597 & 529 & 1304 & 2390 & 766 & 418 \\
\hline 12 & 543 & 541 & 1392 & 1360 & 718 & 735 \\
\hline 13 & 635 & 550 & 597 & 1920 & 1675 & 520 \\
\hline 14 & $503 *$ & 531 * & $1563^{*}$ & $1068 *$ & $639 *$ & $936 *$ \\
\hline 15 & $536 *$ & $526 *$ & $1153^{*}$ & $2580 *$ & $867^{*}$ & $387^{*}$ \\
\hline 16 & 775 & 562 & \multicolumn{4}{|c|}{ Specular microscopy not possible } \\
\hline Mean & 620 & 563 & 830 & 2017 & 1317 & 521 \\
\hline
\end{tabular}

$\mathrm{POE}=$ pachymetry of the operated eye; $\mathrm{PFE}=$ pachymetry of the fellow eye; $\mathrm{ECDOE}=$ endothelial cell density of the operated eye; $E C D F E=$ endothelial cell density of the fellow eye; $A C E O E=$ average cell area of the operated eye; ACEFE = average cell area of the fellow eye.

${ }^{*}$ Corneal grafted patients not included in the statistical analysis. 


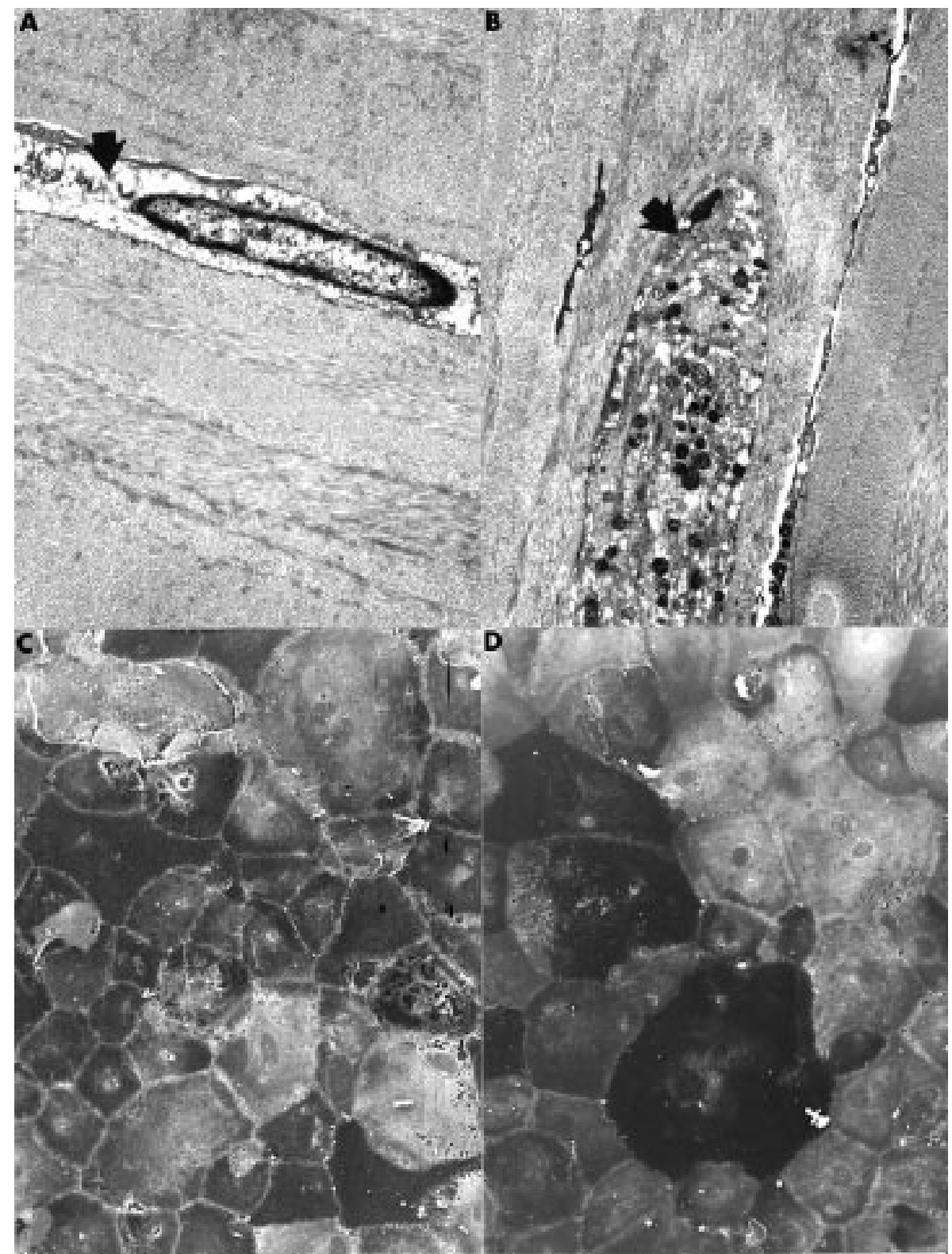

Figure 1 Transmission electron micrographs of the corneal stroma showing representative abnormal keratocytes. One keratocyte has a markedly electron lucent cytoplasm (A from case 14) (arrow); in the other (B) the cytoplasm is distended and contains numerous electron dense bodies (arrow). (A) $\times 6500 ;(B) \times 5100$. Scanning electron micrograph of the corneal endothelium of case 14 (C) and case 15 (D) showing abnormal endothelial cells with a marked variation in shape and size covering a representative portion of Descemet's membrane. (C) $\times 400$; (D) $\times 350$.

difference in the coefficient of variation of cell size $(p=0.3)$ between the study eyes (50\%) and the contralateral eyes $(46 \%)$. All these patients but one had cataract surgery in the fellow eyes.

Comparing the endothelial cell densities of the two eyes and assuming similar endothelial cell densities bilaterally ${ }^{26}$ and similar endothelial cell loss for eyes operated by the same surgeon and with the same technique, we estimated the endothelial cell loss that occurred as a result of the use of BAC preserved viscoelastic. The two grafted patients have been excluded from this calculation as well as case 8 who had cataract surgery in only one eye. The mean endothelial cell density of the operated eyes with BAC preserved HPMC was 844 cells/ $\mathrm{mm}^{2}$ whereas in the contralateral eyes was 1945 cells $/ \mathrm{mm}^{2}$. One could therefore assume that the difference, approximately $57 \%$, in the endothelial cell densities represents the cell loss due to endothelial toxicity of the BAC. In case 12, however, an almost identical endothelial cell density bilaterally may be caused by excessive intraoperative endothelial cell loss in the fellow eye rather than lack of BAC toxicity in the affected eye.

Endothelial cell density of the corneal grafts was 1563 and 1153 cells $/ \mathrm{mm}^{2}$ for cases 14 and 15 respectively; whereas the average cell area was 639 and $867 \mathrm{\mu m}^{2}$ and the coefficient of variation was $32 \%$ and $36 \%$, respectively.

\section{Tissue studies}

The corneal epithelium of both specimens varied in thickness (two to five cells thick) with parts being thinner than normal. Some basal epithelial cells in case 15, but not case 14, were less eosinophilic than normal and several of these cells had a vacuolated cytoplasm. Subepithelial bullae separated portions of the epithelium from the underlying epithelial basal lamina. The peripheral cornea on one side of the specimen from case 14 contained a subepithelial focal accumulation of erythrocytes, but this abnormality was absent in the corneal tissue from the other patient. Bowman's layer, the corneal stroma, 
A

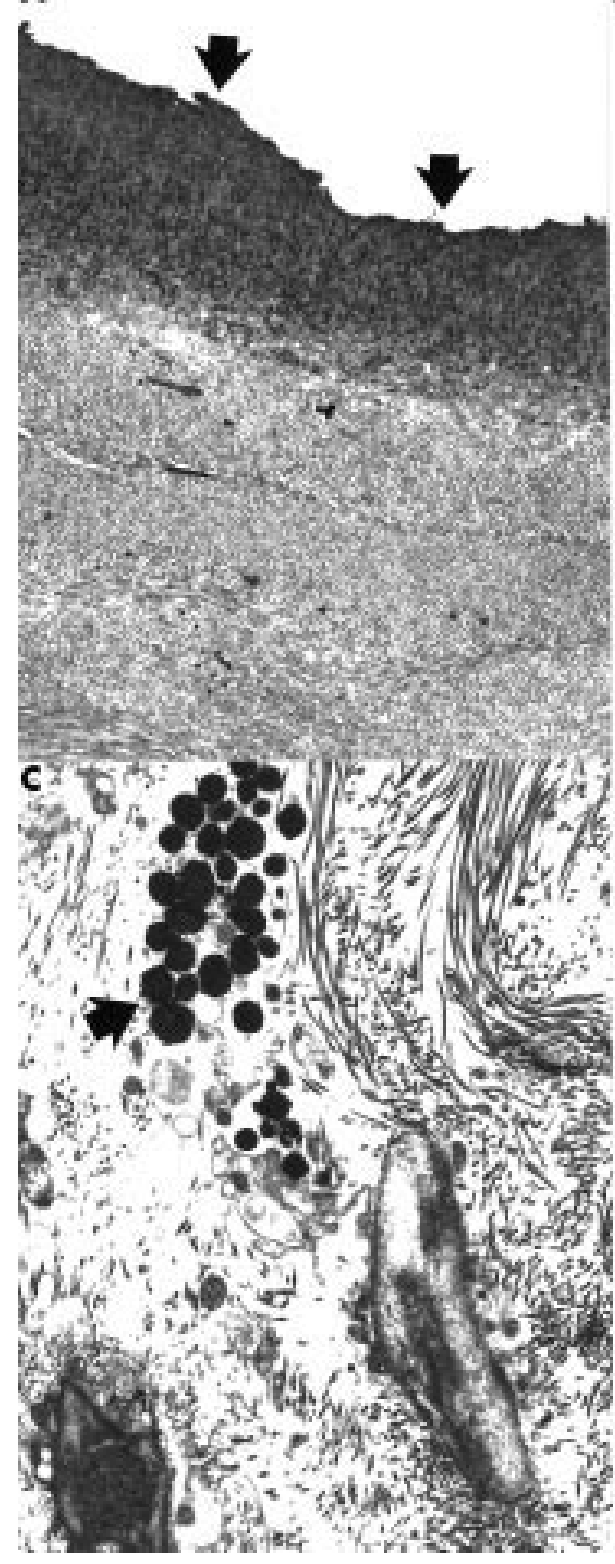

B

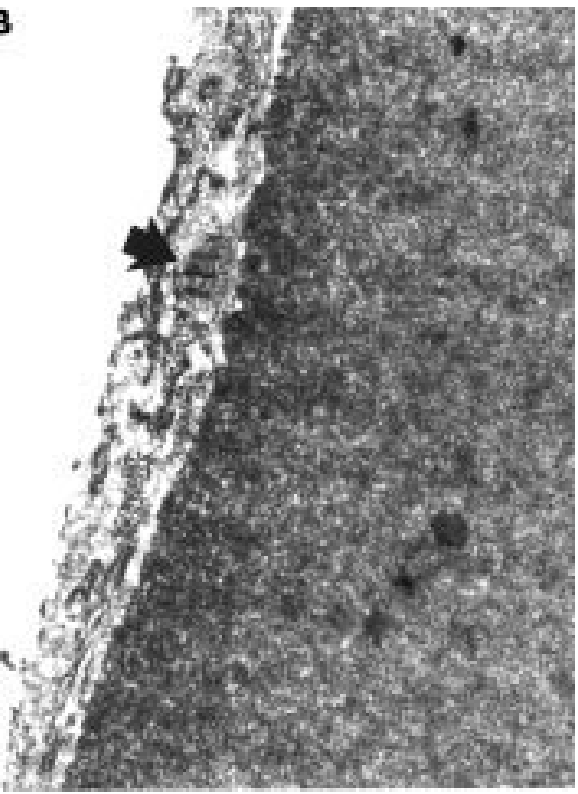

Figure 2 Transmission electron micrographs of the posterior cornea of case $14(\mathrm{~A})$ and case 15 (B) showing abnormal Descemet's membranes. Part of the Descemet's membrane in case 14 had an uneven thickness and ragged posterior surface that lacked endothelial cells A) (arrows). The posterior surface of regions of Descemet's membrane in case 15 was covered with a collagenous layer that contained prominent foci of broad banded collagen (arrow). (A) $\times 7000$; (B) $\times 16000$. (C) Transmission electron micrograph of iris from case 14 showing a cluster of melanosomes within the iris stroma. In contrast with the normal iris these granules are not apparent within the cytoplasm of a melanocyte (arrow) (×5100).

and Descemet's membrane were all unremarkable by light microscopy in both specimens. Particularly noteworthy was the absence of an inflammatory cell infiltrate or vascularisation of the corneal stroma. Although the keratocytes appeared unremarkable by light microscopy, some of them were strikingly abnormal when viewed with the transmission electron microscope (Fig IA and B), because of the presence of numerous electron lucent areas within their cytoplasm. Many keratocytes were in a quiescent stage without morphological evidence of synthetic or phagocytic activity. Transmission electron microscopy also disclosed some broad banded collagen within the corneal stroma.

The corneal endothelial cells were sparse in both specimens and iris tissue was not adherent to the cornea. In case 15 many of the endothelial cells manifest a spindle shape rather than the usual morphological features of the corneal endothelium. Some of these cells contained small brown intracytoplasmic granules, suggestive of melanosomes. Surprisingly, scanning electron microscopy performed on a representative part of the corneal endothelium in both cases disclosed the presence of numerous endothelial cells. The cells, however, varied markedly in size and shape and were not arranged in the usual regular hexagonal pattern that typifies the normal corneal endothelium (Fig IC and D). In some regions endothelial cells were absent and the bare posterior surface of Descemet's membrane could be visualised. This was also noted in transmission electron micrographs from both corneas.

Particularly in case 15 Descemet's membrane was clearly demarcated. The endothelial cells were sparse and the posterior portion of Descemet's membrane was covered by a thin posterior collagenous layer within which broad banded collagen could be identified (Fig 2A and B).

By light microscopy the sampled portions of iris were essentially unremarkable, but in case 14 some melanocytes within the iris stroma lacked an intact cell membrane with the result that scattered extracellular melanocytes could be identified within an otherwise unremarkable corneal stroma (Fig 2C).

\section{DISCUSSION}

BAC corneal toxicity has been demonstrated with many in vivo and in vitro models. ${ }^{4} 1923$ 27-43 It was also reported to inhibit the growth of cultured human trabecular meshwork cells ${ }^{20}$ 
and be toxic to retina and choroid of pigmented rabbits. ${ }^{22}$ Conjunctival, corneal, and anterior uveal changes followed a dose related pattern in animal studies. ${ }^{44}$

Various case reports of corneal endothelial toxicity have been published when BAC preserved medication has been used either on the corneal surface ${ }^{321}$ or intraocularly. ${ }^{24}$

We have tested the toxicity of the BAC preserved HPMC in our cohort using cultured bovine endothelial cells. All cells died within 30 minutes while no damage was observed on treatment of control monolayers or those treated with unpreserved ophthalmic HPMC (unpublished data). In a similar experimental study cultured bovine endothelial cells were killed within 5 minutes by a solution of timolol maleate containing BAC $0.01 \%$ but a dilution of 1:100 did not have any significant effect. ${ }^{45}$ The threshold for physiological and ultrastructural alteration of the rabbit corneal endothelium was reported as approximately $0.0001 \%$ for BAC by Green et $a l^{4}$ and $6.5 \times 10^{-6} \%$ by Hull..$^{23}$

In contrast with the laboratory findings of immediate cell death and despite the initial severity of the striate keratopathy, the corneal oedema of all our study patients, apart from the two patients who underwent penetrating keratoplasty and case 16, has recovered significantly since their operations. Although there is some degree of residual stromal thickening in all these eyes the corneas remain clear. It seems that sufficient remaining endothelial cells can function adequately and restore at least partially the endothelial barrier and the corneal clarity. Another possible explanation for the recovery of the corneal oedema of our cohort is that there is some mitotic activity of the human corneal endothelium. Mitosis of the endothelial cells, although limited, has been described in vivo and in vitro. ${ }^{46-48}$ Unfortunately, morphometric data from the immediate postoperative period are not available for comparison. Use of confocal endothelial microscopy would have been required in the immediate postoperative period to study the endothelial morphology, as specular microscopic analysis necessitates relative clarity of the cornea.

Similarly, Nuyts et a ${ }^{49}$ observed a clinical improvement in a cohort of 10 patients who developed "toxic endothelial cell destruction syndrome" as a result of detergent residue containing non-ionic ethoxylated fatty alcohol in a cannula. They noted in their patients an increase in the endothelial cell density, which they attributed to the reorganisation of the endothelial cells in the cornea and possibly to mitosis.

Although viscoelastics seem not to adsorb drugs when mixed together, ${ }^{50}$ it is unknown what happens when the drugs are already mixed with the viscoelastics in terms of toxicity in the ocular tissues, but one can assume enhanced toxicity, as shown by Ohguro $^{51}$ in an animal model, as a result of prolonged contact especially for dispersive viscoelastics ${ }^{52}$ or sustained release of the drug from the viscoelastic.

The fluffy iris tags observed in two patients are not considered to be related to BAC, as they were bilateral in case 15 and very localised. These may represent a very mild type of iridoschisis. Similarly, the iris transillumination defects have very well demarcated borders and they had the appearance of iris trauma by the phacoemulsification probe. Therefore, we do not believe that those represent signs of toxicity to BAC.

None the less, despite the significant recovery of the corneal oedema all the patients still remain symptomatic. Although symptoms vary considerably in severity, they are very mild in all the patients who can cope very well without the need for any additional treatment. A possible explanation is the toxic effect of BAC to the corneal and anterior uveal innervation. However, this cannot explain the symptoms in the contralateral eyes.

The corneal grafts of the two patients who underwent penetrating keratoplasty are clear. Nevertheless, despite the visual improvement of these patients they are still symptomatic although no apparent reason can be found.

As the corneal oedema in the majority of our patients recovered spontaneously, although in several cases it took sev- eral months, it seems reasonable to suggest that penetrating keratoplasty should be deferred as long as possible anticipating recovery. However, if there is severe and symptomatic bullous keratopathy and penetrating keratoplasty is considered necessary the results are good, although this may not alleviate the symptoms completely.

The abnormalities found in the tissue studies in the corneas of the two patients who underwent penetrating keratoplasty contained abnormalities in the corneal stroma, Descemet's membrane, and the corneal endothelium. Although these findings were non-specific they did provide evidence of cell damage to the corneal stroma, Descemet's membrane, and the corneal endothelium. While the cause of the damage could not be determined from the nature of the abnormalities the findings were consistent with previous chemical injury caused by BAC exposure as was known to have occurred. A noteworthy finding was the presence of at least some intact corneal endothelial cells, suggesting that some recovered at least partially and were able to cover parts of Descemet's membrane. The covering, however, was characterised by cells that varied considerably in size and shape. The presence of extracellular melanosomes within the iris presumably followed a disruption of the cell membrane of melanocytes following BAC exposure.

Despite the clarity of the corneas of almost all our patients after 1 year, we are concerned about the development of corneal decompensation in the future owing to the additional age related endothelial cell loss and we continue to monitor this cohort at regular intervals.

\section{ACKNOWLEDGEMENTS}

A part of this study was supported by the Core Grant for Vision Research at Duke University (P30 EY05722).

\section{Authors' affiliations}

H Eleftheriadis, M Cheong, P P Syam, P Brittain, C Liu, Sussex Eye Hospital, Eastern Road, Brighton BN2 5BF, UK

S Sandeman, A Lloyd, School of Pharmacy and Biomolecular Sciences, University of Brighton, Moulsecoomb, Brighton BN2 4GJ, UK

G K Klintworth , Duke University Medical Center, Durham, NC 27710, USA

\section{REFERENCES}

1 Anders N, Wollensak J. Inadvertent use of chlorhexidine instead of balanced salt solution for intraocular irrigation. J Cataract Refract Surg 1997;23:959-62.

2 Courtright $\mathbf{P}$, Lewallen S, Holland SP, et al. Corneal decompensation after cataract surgery. An outbreak investigation in Asia. Ophthalmology 1995; 102:1461-5

3 Lemp MA, Zimmerman LE. Toxic endothelial degeneration in ocular surface disease treated with topical medications containing benzalkonium chloride. Am J Ophthalmol 1988;105:670-3.

4 Green K, Hull DS, Vaughn ED, et al. Rabbit endothelial response to ophthalmic preservatives. Arch Ophthalmol 1977;95:2218-21.

5 Hull DS, Chemotti MT, Edelhauser HF, et al. Effect of epinephrine on the corneal endothelium. Am J Ophthalmol 1975;79:245-50.

6 Jay JL, MacDonald M. Effects of intraocular miotics on cultured bovine corneal endothelium. Br J Ophthalmol 1978;62:815-20.

7 McDermott ML, Wang J, Shin DH. Mitomycin and the human cornea endothelium. Arch Ophthalmol 1994;1 12:533-7.

8 Mannis MJ, Sweet EH, Lewis RA. The effect of fluorouracil on the corneal endothelium. Arch Ophthalmol 1988;106:816-7.

9 Stoneburner S, Thresher R, Cobo LM, et al. Endothelial cell repopulation after intracameral acetic acid irrigation. Graefes Arch Clin Exp Ophthalmol 1985;223:139-44

10 Edelhauser HF, Van Horn DL, Schultz RO, et al. Comparative toxicity of intraocular irrigating solutions on the corneal endothelium. Am J Ophthalmol 1976;81:473-81.

11 Carter LM, Duncan G, Rennie GK. Effects of detergents on the ionic balance and permeability of isolated bovine cornea. Exp Eye Res 1973;17:409-16.

12 Gonnering R, Edelhauser HF, Van Horn DL, et al. The pH tolerance of rabbit and human corneal endothelium. Invest Ophthalmol Vis Sci 1979;18:373-90

13 Edelhauser HF, Hanneken AM, Pederson HJ, et al. Osmotic tolerance of rabbit and human corneal endothelium. Arch Ophthalmol 1981;99:1281-7. 
14 Patarca R, Fletcher MA. Effects of benzalkonium salts on eukaryotic and microbial G-protein-mediated processes and surface membranes. Crit Rev Oncog 1995;6:327-56.

15 Lapalus $\mathbf{P}$, Ettaiche M, Fredj-Reygrobellet $D$, et al. Cytotoxicity studies in ophthalmology. Lens Eye Toxic Res 1990;7:231-42.

16 De Saint JM, Brignole F, Bringuier AF, et al. Effects of benzalkonium chloride on growth and survival of Chang conjunctival cells. Invest Ophthalmol Vis Sci 1999;40:619-30.

17 Tripathi BJ, Tripathi RC, Kolli SP. Cytotoxicity of ophthalmic preservatives on human corneal epithelium. Lens Eye Toxic Res 1992;9:361-75.

18 Tripathi BJ, Tripathi RC. Cytotoxic effects of benzalkonium chloride and chlorobutanol on human corneal epithelial cells in vitro. Lens Eye Toxic Res 1989;6:395-403.

19 Tonjum AM. Effects of benzalkonium chloride upon the cornea epithelium studied with scanning electron microscopy. Acta Ophthalmol 1975;53:358-66.

20 Samples JR, Binder PS, Nayak S. The effect of epinephrine and benzalkonium chloride on cultured corneal endothelial and trabecular meshwork cells. Exp Eye Res 1989:49:1-12.

21 Gasset AR. Benzalkonium chloride toxicity to the human cornea. Am J Ophthalmol 1977;84:169-71.

22 Chou A, Hori S, Takase M. Ocular toxicity of beta-blockers and benzalkonium chloride in pigmented rabbits: electrophysiological and morphological studies. Jpn J Ophthalmol 1985;29:13-23.

23 Hull DS. Effects of epinephrine, benzalkonium chloride, and intraocular miotics on corneal endothelium. South Med J 1979;72:1380-1.

24 Means TL, Holley GP, Mehta KR, et al. Corneal edema from an intraocular irrigating solution containing benzalkonium chloride. J Toxicol Cut Ocul Toxicol 1994;13:67-81.

25 Laing RA, Sanstrom MM, Berrospi AR, et al. Changes in the corneal endothelium as a function of age. Exp Eye Res 1976;22:587-94.

26 Sturrock GD, Sherrard ES, Rice NS. Specular microscopy of the corneal endothelium. Br J Ophthalmol 1978;62:809-14.

27 Berdy GJ, Abelson MB, Smith LM, et al. Preservative-free artificial tear preparations. Assessment of corneal epithelial toxic effects. Arch Ophthalmol 1992;110:528-32.

28 Doughty MJ. Acute effects of chlorobutanol- or benzalkonium chloride-containing artificial tears on the surface features of rabbit corneal epithelial cells. Optom Vis Sci 1994:71:562-72.

29 Ichijima H, Petroll WM, Jester JV, et al. Confocal microscopic studies of living rabbit cornea treated with benzalkonium chloride. Cornea $1992 ; 11: 221-5$.

30 Pfister RR, Burstein N. The effects of ophthalmic drugs, vehicles, and preservatives on corneal epithelium: a scanning electron microscope study. Invest Ophthalmol 1976;15:246-59.

31 Collin HB, Grabsch BE. The effect of ophthalmic preservatives on the healing rate of the rabbit corneal epithelium after keratectomy. Am J Optom Physiol Opt 1982;59:215-22.

32 Green K, Tonjum AM. The effect of benzalkonium chloride on the electropotential of the rabbit cornea. Acta Ophthalmol 1975;53:348-57.

33 Burstein NL. Preservative alteration of corneal permeability in humans and rabbits. Invest Ophthalmol Vis Sci 1984;25:1453-7.
34 Burstein NL, Klyce SD. Electrophysiologic and morphologic effects of ophthalmic preparations on rabbit cornea epithelium. Invest Ophthalmol Vis Sci 1977; 16:899-911.

35 De Jong C, Stolwijk T, Kuppens E, et al. Topical timolol with and withou benzalkonium chloride: epithelial permeability and autofluorescence of the cornea in glaucoma. Graefes Arch Clin Exp Ophthalmol 1994;232:221-4.

36 Gobbels M, Spitznas M. Corneal epithelial permeability of dry eyes before and after treatment with artificial tears. Ophthalmology 1992;99:873-8

37 Lopez BD, Ubels JL. Quantitative evaluation of the corneal epithelial barrier: effect of artificial tears and preservatives. Curr Eye Res $1991 ; 10: 645-56$

38 Tonjum AM. Permeability of rabbit corneal epithelium to horseradish peroxidase after the influence of benzalkonium chloride. Acta Ophthalmol 1975:53:335-47.

39 Santoul C, Decrovez E, Driot JY, et al. Use of a specular microscope with pachymeter in ocular tolerance studies of eye drops in the rabbit. Evaluation of ocular tolerance of benzalkonium chloride in aqueous solution $0.01 \%$ and $0.1 \%$. Lens Eye Toxic Res 1990;7:359-69.

40 Sasaki H, Nagano T, Yamamura K, et al. Ophthalmic preservatives as absorption promoters for ocular drug delivery. J Pharm Pharmacol 1995;47:703-7.

41 Wilson WS, Duncan AJ, Jay JL. Effect of benzalkonium chloride on the stability of the precorneal tear film in rabbit and man. Br J Ophthalmol 1975;59:667-9.

42 Norn MS, Opauszki A. Effects of ophthalmic vehicles on the stability of the precorneal film. Acta Ophthalmol 1977;55:23-34.

43 Gasset AR, Ishii Y, Kaufman HE, et al. Cytotoxicity of ophthalmic preservatives. Am J Ophthalmol 1974;78:98-105.

44 Britton B, Hervey R, Kasten K, et al. Intraocular irritation evaluation of benzalkonium chloride in rabbits. Ophthalmic Surg 1976;7:46-55.

45 Staatz WD, Radius RL, Van Horn DL, et al. Effects of timolol on bovine corneal endothelial cultures. Arch Ophthalmol 1981;99:660-3.

46 Treffers WF. Human corneal endothelial wound repair. In vitro and in vivo. Ophthalmology 1982;89:605-13.

47 Singh G. Mitosis and cell division in human corneal endothelium. Ann Ophthalmol 1993;18:88-90.

48 Laing RA, Neubauer L, Oak SS, et al. Evidence for mitosis in the adult corneal endothelium. Ophthalmology 1984;91:1129-34.

49 Nuyts RM, Boot N, van Best JA, et al. Long term changes in human corneal endothelium following toxic endothelial cell destruction: a specular microscopic and fluorophotometric study. $\mathrm{Br} J$ Ophthalmol 1996;80:15-20.

50 McDermott ML, Edelhauser HF. Drug binding of ophthalmic viscoelastic agents. Arch Ophthalmol 1989;107:261-3.

51 Ohguro N, Matsuda M, Kinoshita S. The effects of denatured sodium hyaluronate on the corneal endothelium in cats. Am J Ophthalmol $1991 ; 112: 424-30$

52 Glasser DB, Osborn DC, Nordeen JF, et al. Endothelial protection and viscoelastic retention during phacoemulsification and intraocular lens implantation. Arch Ophthalmol 1991;109:1438-40. 